Number of words: 3689

Number of pages: 19

Number of illustrations: 2

Number of tables: 3

\title{
Vibrotactile perception thresholds at the sole of the foot: effects of contact force and probe indentation
}

\author{
Authors: \\ Cheng Gu and Michael J. Griffin \\ Human Factors Research Unit \\ Institute of Sound and Vibration Research \\ University of Southampton \\ Southampton, SO17 1BJ \\ England
}

Corresponding author:

Professor Michael J. Griffin

Human Factors Research Unit

Institute of Sound and Vibration Research

University of Southampton

Southampton, SO17 1BJ

England

Tel: +44 (0)23 80592277

Fax: +44 (0)23 80592927

e-mail:m.j.griffin@soton.ac.uk

Key words:

Vibration; thresholds; force; indentation; foot; toe; frequency; neuropathy. 


\begin{abstract}
When using vibrotactile thresholds to investigate neuropathy in the fingers, the indentation of a vibrating probe, and the force applied to a static surround around a vibrating probe, affect thresholds. This study was designed to investigate the effects on vibrotactile perception thresholds at the sole of the foot of probe indentation (i.e. height of a vibrating probe relative to a static surround) and the force applied to the static surround. Thresholds at $20 \mathrm{~Hz}$ (expected to be mediated by the NP I channel) and at $160 \mathrm{~Hz}$ (expected to be mediated by the Pacinian channel) were obtained at the hallux (i.e. greater toe) and the ball of the foot on 14 healthy subjects. In one condition, the height of the vibrating probe was varied to $0,1,2,3$, and $4 \mathrm{~mm}$ above a static surround with $4-\mathrm{N}$ force applied to the surround. In a second condition, the force applied to the surround was varied to $1,2,3,4,5$, and $6 \mathrm{~N}$ while using a probe height of $1 \mathrm{~mm}$. Thresholds at $20 \mathrm{~Hz}$ decreased with increasing probe height from 0 to $1 \mathrm{~mm}$ but showed no significant variation between 2, 3, and $4 \mathrm{~mm}$ at either the hallux or the ball of the foot. Thresholds at $160 \mathrm{~Hz}$ decreased with increasing probe height from 0 to $4 \mathrm{~mm}$ at both the hallux and the ball of the foot. Thresholds at $20 \mathrm{~Hz}$ obtained with 1-N surround force were higher than thresholds obtained with $2 \mathrm{~N}$, but there was no significant difference with surround forces from 2 to $6 \mathrm{~N}$ at either the hallux or the ball of the foot. Thresholds at $160 \mathrm{~Hz}$ were unaffected by variations in surround force at the ball of the foot but tended to decrease with increasing force at the hallux. It is concluded that a vibrating probe flush with a static surround, and a surround force in the range 2 to $4 \mathrm{~N}$, are appropriate when measuring vibrotactile thresholds at the hallux and the ball of the foot with a $6-\mathrm{mm}$ diameter contactor and a 2-mm gap to the static surround.
\end{abstract}




\section{Introduction}

Vibrotactile thresholds at the foot are used to monitor peripheral neuropathy associated with diabetes [1-6]. Thresholds are determined using a wide variety of different equipment with differing complexity and varying specifications of the frequency of the vibration and the contact conditions. Since vibration thresholds depend on various factors including the frequency of vibration and the contact conditions, thresholds determined by one system differ from those determined by other systems. With changes in the frequency of the vibration and the contact conditions, different receptors and different psychophysical channels become responsible for the mediation of vibration sensations, so different tests not only have differing normal values but also indicate different forms of neuropathy. The research reported here sought to contribute to the information needed to standardise conditions appropriate for the investigation of neuropathy at the foot when using vibrotactile thresholds.

Although there is widespread clinical application of vibrotactile thresholds at the foot, most systematic research on vibrotactile thresholds has been undertaken at the hand. Thresholds for the perception of vibration at the glabrous skin of the human hand are mediated by four mechanoreceptor channels: a Pacinian channel and three non-Pacinian channels $[7,8]$. The principal channels are usually the non-Pacinian channel I (NP I channel), generally mediating thresholds from 10 to $40 \mathrm{~Hz}$, and the Pacinian channel having a U-shaped contour of displacement sensitivity over the frequency range 40 to $800 \mathrm{~Hz}$ with maximum sensitivity to displacement around 250 or $300 \mathrm{~Hz}$ [7-9].

Many factors have been found to influence vibrotactile thresholds at the glabrous skin of the hand, such as skin temperature [10], contact area [11], contact pressure [12], and skin indentation [13]. Verrillo [14] investigated vibrotactile thresholds at the first metacarpal of the thumb (thenar eminence) with three probe heights: $0.5 \mathrm{~mm}$ below a static surround, $0.5 \mathrm{~mm}$ above the surround, and $1.5 \mathrm{~mm}$ above the surround. It was found that thresholds decreased as a function of increasing probe height when perception of 80,160 , and $320-\mathrm{Hz}$ vibration was mediated by the Pacinian channel [7]. Similarly, increasing the height of a probe from $4 \mathrm{~mm}$ below a surround to $2 \mathrm{~mm}$ above the surround has been found to decrease $210-\mathrm{Hz}$ thresholds at both the fingertip and the thenar eminence [15]. In the same study, sensitivity to $18-\mathrm{Hz}$ vibration at the thenar eminence increased slightly with increasing probe height from $2 \mathrm{~mm}$ below the surround to $2 \mathrm{~mm}$ above the surround. At the fingertip, sensitivity to $18-\mathrm{Hz}$ vibration increased with increasing probe height from $3 \mathrm{~mm}$ below the surround to around $1 \mathrm{~mm}$ below a surround, and then decreased with probe height from 1 $\mathrm{mm}$ below the surround to $2 \mathrm{~mm}$ above the surround. Makous et al. [16] investigated the effects of static indentation of skin $(0,0.25,0.5,0.75$, and $1 \mathrm{~mm})$ at the thenar eminence on 
the perception of vibration and found thresholds at 20 and $200 \mathrm{~Hz}$ decreased with increased indentation, consistent with Lamoré and Keemink [15]. These studies suggest that with increased skin indentation caused by increased probe height, sensitivity determined by the Pacinian channel increases (i.e. thresholds reduce with increasing probe height), whereas thresholds determined by the NP I channel may be differently affected at the fingertip and the thenar eminence.

The force applied to the static surround around a vibrating probe might also be expected to influence vibrotactile thresholds. Lindsell [13] investigated thresholds at the fingertip with 1-, 2- and 3-N surround forces and found that increasing the surround force marginally increased $125-\mathrm{Hz}$ thresholds mediated by the Pacinian channel, but had no effect on 31.5$\mathrm{Hz}$ thresholds mediated by the NP I channel. With surround forces increasing from 0.25 to 3 $\mathrm{N}$, slight, but not statistically significant, increases in $125-\mathrm{Hz}$ thresholds have been reported at the fingertip [17].

Although there has been some study of the influence of subject characteristics on vibrotactile thresholds at the sole of the foot (e.g., effects of gender, age, body size and skin temperature, [18]), the influence of contact conditions on vibration perception at the foot has received little attention. It has been shown that the Pacinian channel is likely to mediate sensations at threshold levels between about 40 and $250 \mathrm{~Hz}$, while the NP I channel is likely to mediate sensations between 20 and $40 \mathrm{~Hz}$ [19]. The present experimental study was designed to investigate whether thresholds determined by the Pacinian channel and the NP I channel at the sole of the foot depend on probe height and surround force. It was hypothesized that thresholds at both $20 \mathrm{~Hz}$ (NP I channel) and $160 \mathrm{~Hz}$ (Pacinian channel) would decrease with increasing probe height, and that thresholds at $20 \mathrm{~Hz}$ would be unaffected by surround force while thresholds at $160 \mathrm{~Hz}$ would increase with increasing surround force. It was hoped that the findings of the study would assist the selection of a suitable force on the surround so that small changes in force would not result in large changes in threshold.

\section{Materials and Methods}

\subsection{Subjects}

Fourteen male University staff and students (aged $27 \pm 2$ years) with no history of neuropathy participated in the study. The subjects read instructions and gave consent before commencing the experiment that was approved by the Human Experimentation Safety and Ethics Committee of the ISVR at the University of Southampton.

\subsection{Experiment conditions}


Vibrotactile thresholds were measured using an HVLab vibrotactile perception meter (HVLab, ISVR, University of Southampton). This apparatus uses a vibrating probe that can be adjusted to a desired 'height' relative to a stationary surround. The surround controls the area excited by vibration, creates a 'gradient' that enhances perception via the NPI channel, and prevents the vibration from being transmitted to, and perceived at, distant locations. With a controlled force applied to the surround, the 'height' of the probe controls the force applied to the skin by the probe. The diameter of the probe was $6 \mathrm{~mm}$ and the gap between the probe and a fixed circular surround was $2 \mathrm{~mm}$. The external diameter of the flat surround was $26 \mathrm{~mm}$. Vibrotactile thresholds were obtained at the hallux (i.e. greater toe) and the ball of the foot at 20 and $160 \mathrm{~Hz}$ with different surround contact forces and different heights of the probe relative to the fixed surround.

Thresholds were determined with each of six surround forces $(1,2,3,4,5$ and $6 \mathrm{~N})$ using a probe $1 \mathrm{~mm}$ above the surround. Thresholds were also determined with each of five probe heights $(0,1,2,3$ and $4 \mathrm{~mm}$ relative to the surround) using a surround contact force of $4 \mathrm{~N}$. Half of the subjects were tested first at the hallux and half were tested first at the ball of the foot. Similarly, half were tested first at $20 \mathrm{~Hz}$ and half were tested first at $160 \mathrm{~Hz}$. The order of presenting the six forces or the five probe heights was randomized across subjects.

\section{TABLE 1 ABOUT HERE}

Subjects lay supine on a couch with their left leg resting horizontally and their left foot vertical and uncovered. The applicator of the vibrotactile perception meter was applied against the sole of the left foot by the experimenter. To avoid bending the toe when applying $4 \mathrm{~N}$, the experimenter held the other side of the hallux using fingers. The experiment was conducted in two sessions. In one session, thresholds were obtained at the whorl of the hallux on the plantar surface (i.e. at the centre of the spiral patter of ridges); in the other session, thresholds were obtained on the plantar surface of the ball of the foot close to the metatarsal heads (about $4 \mathrm{~cm}$ from the right side of the foot and $4 \mathrm{~cm}$ to the rear of crotch between the hallux and the adjacent toe).

The von Békésy method was employed to determine the vibrotactile threshold. The rate of change of vibration magnitude was initially $5 \mathrm{~dB} /$ second but reduced to $3 \mathrm{~dB} /$ second after the subject first felt vibration and pressed the response button. While the button was depressed, the vibration magnitude decreased at $3 \mathrm{~dB} /$ second until the subject felt no vibration and released the button. The vibration magnitude then increased at $3 \mathrm{~dB} / \mathrm{second}$ until the subject felt vibration and again pressed the button. The measurements continued for a minimum of 30 seconds and until a minimum of six pairs of reversals had been obtained, excluding the first pair of reversals. Thresholds were determined from the 
arithmetic averages of the logarithms of the root-mean-square vibration acceleration at the reversals (i.e. a minimum of six reversals). This method has been standardised for determining vibrotactile thresholds at the fingers (e.g. [20]). In accord with International Standard 13091-1:2001 [21], thresholds are expressed in root-mean-square acceleration ( $\mathrm{ms}^{-2}$ r.m.s.). Because sinusoidal stimuli were used, the thresholds may be converted to r.m.s. displacement by dividing by $(2 \pi f)^{2}$, where $f$ is the frequency of the vibration (either 20 or $160 \mathrm{~Hz}$ ). The peak-to-peak displacement can be calculated by multiplying the r.m.s. displacement (in metres) by $2 \sqrt{ } 2$.

The room temperature was $25 \pm 2^{\circ} \mathrm{C}$. The temperature of the skin was measured at the hallux and at the ball of the foot using a thermocouple so as to check that it was greater than $25^{\circ} \mathrm{C}$ in all subjects throughout the experiment.

\subsection{Statistical methods}

Results were analysed using the Statistical Package for the Social Sciences (SPSS) version 14.0. Friedman tests and Wilcoxon signed ranks tests were employed to study differences between probe heights, surround forces, and contact locations.

\section{Results}

\subsection{Effect of probe height}

At both the ball of the foot and the hallux, the thresholds at both $20-\mathrm{Hz}$ and $160-\mathrm{Hz}$ vibration tended to fall with increasing probe height (Figure 1).

\section{FIGURE 1 ABOUT HERE}

\section{0-Hz thresholds}

With $20-\mathrm{Hz}$ vibration, there was a significant difference between thresholds measured with the five different probe heights at both the hallux and the ball of the foot $(p<0.001$; Friedman). Thresholds obtained with the $0-\mathrm{mm}$ probe height (probe flush with the surround) were higher than thresholds obtained with $1-$ to $4-\mathrm{mm}$ probe heights $(p<0.002$; Wilcoxon; Table 2). Thresholds obtained with $1-\mathrm{mm}$ probe height were generally significantly higher than thresholds obtained with 3- and 4-mm probe heights, but not significantly higher than those obtained with the 2-mm probe height (Table 2). There were no significant differences between thresholds obtained with 2- to 4-mm probe heights (Table 2).

160-Hz thresholds

With $160-\mathrm{Hz}$ vibration, there was a significant difference between thresholds measured with the five different probe heights at both the hallux and the ball of the foot $(p<0.001$; 
Friedman). Thresholds decreased significantly with increased probe height from $0 \mathrm{~mm}$ to 4 $\mathrm{mm}$ at the two locations (Table 2).

\section{TABLES 2 ABOUT HERE}

\subsection{Effect of surround force}

At both the ball of the foot and the hallux, the thresholds at both $20 \mathrm{~Hz}$ and $160 \mathrm{~Hz}$ showed a slight trend to fall with increasing force applied to the surround around the vibrating probe (Figure 2).

\section{FIGURE 2 ABOUT HERE}

\section{0-Hz thresholds}

With $20-\mathrm{Hz}$ vibration, there was a significant difference between the thresholds measured with the six different surround forces (at the hallux: $p=0.001$; at the ball of the foot: $p=$ 0.044; Friedman). Vibrotactile thresholds measured with $1-\mathrm{N}$ force were higher than thresholds measured at higher forces, except for the comparison between 1 and $2 \mathrm{~N}$ at the ball of the foot (Table 3). Thresholds obtained with 2-N force were higher than thresholds obtained with 5 and $6-\mathrm{N}$ force at the hallux, but only higher than thresholds obtained with 6 $\mathrm{N}$ at the ball of the foot (Table 3). There was no significant difference between thresholds obtained with 4,5 , and $6 \mathrm{~N}$ at the hallux or the ball of the foot, except between 4 and $6 \mathrm{~N}$ at the hallux (Table 3).

\section{0-Hz thresholds}

With $160-\mathrm{Hz}$ vibration, there was also a significant difference between the thresholds measured with the six different surround forces at the hallux ( $p<0.001$; Friedman). There was no significant difference between thresholds obtained with the forces from 1 to $3 \mathrm{~N}$ ( $p \geq$ 0.158; Wilcoxon), but thresholds obtained with 1,2 and $3 \mathrm{~N}$ were higher than thresholds obtained with forces from 4 to $6 \mathrm{~N}$, except between 3 and $4 \mathrm{~N}$ (Table 3). There was no significant difference between the thresholds measured with 4,5 , and $6 \mathrm{~N}$, except between 5 and $6 \mathrm{~N}$ (Table 3).

With $160-\mathrm{Hz}$ vibration, there was no significant difference between thresholds measured with six different contact forces at the ball of the foot ( $p=0.481$; Friedman).

\section{TABLE 3 ABOUT HERE}

\subsection{Effect of contact location}

With $20-\mathrm{Hz}$ vibration, there were no significant differences between thresholds obtained at the hallux and the ball with the same force and probe height ( $p>0.05$; Wilcoxon). 
With $160-\mathrm{Hz}$ vibration, thresholds at the hallux were significantly higher than thresholds at the ball with each of the six forces ( $p \leq 0.022$; Wilcoxon) and with probe heights in the range 0 to $2 \mathrm{~mm}(p \leq 0.035)$. There was no significant difference between thresholds obtained at the hallux and the ball when using either a 3 or $4-\mathrm{mm}$ probe $(p>0.05)$ although 11 of the 14 subjects showed higher thresholds at the hallux with the 3-mm probe and 10 of the 14 subjects showed higher thresholds at the hallux with the 4-mm probe.

\section{Discussion}

\subsection{Effect of probe height}

At both the hallux and the ball of the foot, the $20-\mathrm{Hz}$ thresholds decreased with increasing probe height from 0 to $2 \mathrm{~mm}$, and then remained unaffected as the height of the probe increased from 2 to $4 \mathrm{~mm}$. This is broadly consistent with changes in thresholds at the thenar eminence as reported by Makous et al. [16] using $20-\mathrm{Hz}$ vibration and Lamoré and Keemink [15] using 18- $\mathrm{Hz}$ vibration. Lamoré and Keemink found that $18-\mathrm{Hz}$ thresholds at the thenar eminence decreased as the probe height increased from $2 \mathrm{~mm}$ below a surround to being level with the surround (i.e. $0 \mathrm{~mm}$ ), and then remained unchanged as the probe height increased from $0 \mathrm{~mm}$ to $2 \mathrm{~mm}$ above the surround. Makous et al. show a reduction in $20-\mathrm{Hz}$ thresholds as the height of a probe increased from 0 to $0.5 \mathrm{~mm}$ above a surround, and then a slower reduction as the probe height increased from 0.5 to $1 \mathrm{~mm}$.

Increasing the probe force increases skin indentation, although the extent of the indentation will depend on the dimensions of the probe and the surround [13,22]. The present study of the effects of probe height can therefore be compared with studies of the effects of probe force where the contact conditions have been similar. Increasing the probe height from 0 to $2 \mathrm{~mm}$ in the current study produced a similar change in $20-\mathrm{Hz}$ thresholds to that reported by Lindsell [13] for $31.5-\mathrm{Hz}$ thresholds when the probe contact force was increased from 0.5 to 2 N. Harada and Griffin [12] reported a similar, although not statistically significant, trend with $31.5-\mathrm{Hz}$ thresholds as the probe force increased from 1 to $3 \mathrm{~N}$.

With increasing probe height, the decrease in $160-\mathrm{Hz}$ thresholds at the hallux and the ball of the foot in the present study is consistent with a decrease in $160-\mathrm{Hz}$ thresholds at the thenar eminence reported by Verrillo [14], a decrease in $210-\mathrm{Hz}$ thresholds at both the fingertip and the thenar eminence reported by Lamoré and Keemink [15], and a decrease in $200-\mathrm{Hz}$ thresholds at the thenar eminence reported by Makous et al. [16]. These decreases are also consistent with the decrease in $125-\mathrm{Hz}$ thresholds as the probe force increased from 0.5 to $2 \mathrm{~N}$, as reported by Lindsell [13]. Increased sensitivity with increasing probe height might arise from the skin following the probe more closely when there is greater force and greater 
indentation [23]. It has been reported that skin motion is more similar to probe motion when there is pre-indentation of the skin, with increased peak-to-peak skin excursion when using $0.5 \mathrm{~mm}$ pre-indentation compared to no pre-indentation [24]. The responses of the local tissues and the receptors may also be changed by increasing the probe height or the probe force.

With $20-\mathrm{Hz}$ vibration, the rates of decrease in threshold with increased probe height were 1.22 and $-1.50 \mathrm{~dB} / \mathrm{mm}$ for the hallux and the ball, respectively. With $160-\mathrm{Hz}$ vibration, the corresponding rates were -3.41 and $-4.11 \mathrm{~dB} / \mathrm{mm}$, almost three times the rate with $20-\mathrm{Hz}$ vibration. The large difference is consistent with vibrotactile perception at the sole of the foot being mediated by different mechanoreceptor channels at 20 and $160 \mathrm{~Hz}$.

With increasing probe height, the inter-subject variability decreased, but a high probe height is undesirable because it is increasingly difficult to apply a constant force on the surround as the probe height increases, especially with probe heights greater than about $3 \mathrm{~mm}$. To maintain consistency with the method used to measure thresholds at the fingertip [25,26], the present results suggest it would be reasonable to set the probe flush with the static surround (i.e. a probe height of $0 \mathrm{~mm}$ ) when measuring vibrotactile thresholds at the foot. It might be better to control skin indentation rather than probe height relative to a surround, but this is currently difficult to achieve in equipment suitable for a clinical environment.

\subsection{Effect of surround force}

When investigating the effect of surround force in this study, the probe height was fixed at 1 $\mathrm{mm}$, so increases in the force on the surround increased the force on the probe. There may have been different effects of varying the surround force on thresholds if the probe force had not varied. Piercy and Brammer [22] investigated the effect of probe contact force on probe indentation at the fingertip using a 4-mm diameter probe with and without a 7-mm diameter surround (1.5 mm gap). With very low probe forces $(0.025 \mathrm{~N}$ to $0.6 \mathrm{~N})$ and a $1-\mathrm{N}$ force on the surround, it was found that the presence of the surround stiffened the flesh at the fingertip. Although much greater forces were used in the present study it is likely that the stiffness of the skin increased when the surround contact force was increased. Although there was no direct evidence of a relation between surround force, stiffness of the skin, and thresholds, Lindsell [13] observed that increasing the surround force increased thresholds.

The $20-\mathrm{Hz}$ thresholds obtained at the hallux and the ball of the foot were significantly higher with a surround force of $1 \mathrm{~N}$ than with forces from 2 to $6 \mathrm{~N}$. According to Lindsell [13], when varying the surround force and probe force separately, the surround force has no clear effect on low frequency thresholds, so the increase in thresholds obtained with the 1-N surround force in the present study may have been caused by the associated increase in 
the probe force as the surround force increased. The absence of a change in $20-\mathrm{Hz}$ thresholds at the hallux and the ball of the foot as the surround forces increased from 2 to 6 $\mathrm{N}$ is consistent with the absence of an effect of surround force on $31.5-\mathrm{Hz}$ thresholds at the fingertip [13]. This implies that any change in probe force as the surround force increased from 2 to $6 \mathrm{~N}$, was not sufficient to change thresholds.

The $160-\mathrm{Hz}$ thresholds obtained at the ball of the foot with surround forces from 1 to $6 \mathrm{~N}$ showed no significant difference, although there was a trend towards decreasing thresholds with increasing surround force. At the hallux, the $160-\mathrm{Hz}$ thresholds decreased significantly as the surround force increased from 1 to $6 \mathrm{~N}$. These findings at the hallux and the ball of the foot are not consistent with the increase in thresholds with increased surround force at the hand $[13,17]$. This may be because in the present study the increased surround force was accompanied by increased probe force (due to the fixed height of the probe relative to the surround), and the increase in probe force had a dominant influence in reducing the threshold as the surround force increased.

The forces applied during threshold determinations will vary, especially if the experimenter or subject lose concentration or change posture. It would assist the reproducibility of thresholds if the test conditions minimised the effect on thresholds of variations in the surround force. There were consistent and statistically significant effects of surround force, although the overall influence of surround force was small relative to the influence of probe height. The effects of force appear larger and more consistent with low forces, but high forces are less convenient, especially when measuring at the toe. Inter-subject variability was not increased or reduced by varying the surround force, so inter-subject variability does influence the selection of surround force. Thresholds obtained with forces of 2, 3, or $4 \mathrm{~N}$ (in the middle of the investigated range) were not significantly different at either the hallux or the ball of the foot with either $20-\mathrm{Hz}$ or $160-\mathrm{Hz}$ vibration. A surround force in this range seems both appropriate and convenient for the measurement of vibrotactile thresholds at the hallux and the ball of the foot when using a 6-mm diameter contactor with a 2-mm gap to a static surround.

\section{Conclusions}

At both the toe and the ball of the foot, $20-\mathrm{Hz}$ vibrotactile thresholds (mediated by the NP I channel) decrease as the probe height increases from $0 \mathrm{~mm}$ (probe flush with a static surround) to $1 \mathrm{~mm}$ above the surround, but thresholds are little affected by further increases in probe height to $4 \mathrm{~mm}$. Thresholds at $160 \mathrm{~Hz}$ (Pacinian channel) decrease as the probe height increases from $0 \mathrm{~mm}$ to $4 \mathrm{~mm}$. When using a probe with a fixed height relative to a fixed surround, thresholds at the hallux and the ball of the foot tend to decrease with 
increasing force applied to the fixed surround, possibly due to an associated increase in force on the probe rather than the increased force on the surround. A probe flush with a static surround and a surround force in the range 2 to $4 \mathrm{~N}$ seem appropriate for measuring vibrotactile thresholds at both the hallux and the ball of the foot when using a 6-mm diameter contactor with a 2-mm gap to a static surround.

\section{Conflict of interest statement}

The authors report no conflict of interest. 


\section{References}

[1] Bergenheim T, Borssén B, and Lithner F Sensory thresholds for vibration, perception and pain in diabetic patients aged $15-50$ years. Diabetes Research and Clinical Practice 1992; 16:47-52.

[2] Coppini DV, Wellmer A, Weng C, Young PJ, Anand P, Sonksen PH The natural history of diabetic peripheral neuropathy determined by a 12 year prospective study using vibration perception thresholds. Journal of Clinical Neuroscience 2001; 8: 520-524

[3] Davis EA, Jones TW, Walsh P, and Byrne GC The use of biothesiometry to detect neuropathy in children and adolescents with IDDM. Diabetes Care 1997; 20(9):14481453.

[4] Dyck PJ, Bushek W, Spring E, Karnes JL, Litchy WJ, O'Brien PC, and Service FJ Vibratory and cooling detection thresholds compared with other tests in diagnosing and staging diabetic neuropathy. Diabetes Care 1987; 10(4): 432-440.

[5] Garrow AP and Boulton AJM Vibration perception threshold - a valuable assessment of neural dysfunction in people with diabetes. Diabetes Metab Res Rev 2006; 22:411-419.

[6] Young MJ, Breddy JL, Veves A, Boulton AJM The prediction of diabetic neuropathic foot ulceration using vibration perception thresholds A prospective study. Diabetes Care 1994; 16(6): 557-560.

[7] Bolanowski SJ, Jr., Gescheider G A, Verrillo R T, Checkosky C M Four channels mediate the mechanical aspects of touch. Journal of Acoustical Society of America 1988; 84(5), 1680-1694.

[8] Gescheider GA, Bolanowski SJ, Pope JV and Verrillo RT A four-channel analysis of the tactile sensitivity of the fingertip: frequency selectivity, spatial summation, and temporal summation, Somatosensory \& Motor Research 2002; 19(2):114-124

[9] Verrillo RT A duplex mechanism of mechanoreception. In D. R. Kenshalo (Ed.), The Skin Senses. Springfield, III: Thomas, 1968; 139-159.

[10] Bolanowski SJ, Jr., Verrillo RT Temperature and criterion effects in a somatosensory subsystem: a neurophysiological and psychophysical study. Journal of Neurophysiology 1982; 48(3):836-855

[11] Verrillo RT Effect of contactor area on the vibrotactile threshold. Journal of Acoustical Society of America 1963; 35(12), 1962-1966. 
[12] Harada N and Griffin MJ Factors influencing vibration sense thresholds used to assess occupational exposures to hand transmitted vibration. British Journal of Industrial Medicine 1991; 48, 185-192.

[13] Lindsell CJ Vibrotactile thresholds: effect of contact forces and skin indentation. UK Group Meeting on Human Response to Vibration, 17-19 September, 1997; Southampton, England.

[14] Verrillo RT Investigation of some parameters of the cutaneous threshold for vibration, The Journal of The Acoustical Society of America 1962; 34(11):1768-1773

[15] Lamoré PJJ and Keemink CJ Evidence for different types of mechanoreceptors from measurements of the psychophysical threshold for vibrations under different stimulation conditions, The Journal of The Acoustical Society of America 1988; 3(6):2339-2351

[16] Makous JC, Gescheider GA and Bolanowski SJ The effect of static indentation on vibrotactile threshold. Journal of Acoustical Society of America 1996; 99(5):3149-3153

[17] Maeda S, Yonekawa $Y$, Kanada $K$ and Takahashi $Y$ Effects of push forces on vibrotactile thresholds measurement. 8th International Conference on Hand-Arm Vibration, 9-12 June 1998, Umeå, Sweden.

[18] Hilz MJ, Axelrod FB, Hermann K, Haertl U, Duetsch M, Neundörfer B Normative values of vibratory perception in 530 children, juveniles and adults aged 3-79 years. Journal of the Neurological Sciences, 1998, 159, 2, 219-225.

[19] Gu C and Griffin MJ Effect of frequency and contact location on vibrotactile perception thresholds at the foot. 11th International Conference on Hand-Arm Vibration, 3-7 June 2007, Bologna, Italy.

[20] Lindsell CJ, Griffin MJ, Normative data for vascular and neurological tests of the handarm vibration syndrome. International Archives of Occupational and Environmental Health 2002; 75(1-2), 43-54.

[21] International Organization for Standardization. Mechanical vibration - Vibrotactile perception thresholds for the assessment of nerve dysfunction - Part 1: Methods of measurement at the fingertips. ISO 13091-1 (Geneva), 2001.

[22] Piercy JE and Brammer AJ Equivalent skin-stimulator contact forces for vibrotactile measurements with, and without, a surround. 8th International Conference on HandArm Vibration, 9-12 June 1998, Umeå, Sweden.

[23] Brisben AJ, Hsiao SS, Johnson KO Detection of vibration transmitted through an object grasped in the hand. Journal of Neurophysiology 1999; 81: 1548-1558. 
[24] Goodwin AW, John KT, Darian-Smith I Skin profiles during sinusoidal vibration of the fingerpad. Experimental Brain Research 1989; 77:79-86

[25] Morioka M, Whitehouse DJ and Griffin MJ Vibrotactile thresholds at the fingertip, volar forearm, large toe, and heel. Somatosensory \& Motor Research 2008; 25(2):101-112.

[26] Seah SA, Griffin MJ Normal values of thermotactile and vibrotactile thresholds in males and females. International Archives of Occupational and Environmental Health 2008; 81(5):535-543. 
Table 1 Parameters of vibrotactile threshold measurement.

\begin{tabular}{|c|c|c|}
\hline \multicolumn{3}{|l|}{ Test Stimuli } \\
\hline Frequency $(\mathrm{Hz})$ & \multicolumn{2}{|c|}{20,160} \\
\hline Test duration (seconds) & \multicolumn{2}{|c|}{30} \\
\hline \multicolumn{3}{|l|}{ Algorithm } \\
\hline Psychophysical method & \multicolumn{2}{|c|}{ von Békésy } \\
\hline Initial increment rate & \multicolumn{2}{|c|}{$5 \mathrm{~dB} / \mathrm{s}$} \\
\hline Test increment rate & \multicolumn{2}{|c|}{$3 \mathrm{~dB} / \mathrm{s}$} \\
\hline Minimum reversals & \multicolumn{2}{|c|}{6} \\
\hline Subject response & \multicolumn{2}{|c|}{ To press and release response button } \\
\hline \multicolumn{3}{|l|}{ Contac condition } \\
\hline & Probe height session & Surround force session \\
\hline Probe height $(\mathrm{mm})$ & $0,1,2,3$ and 4 & 1 \\
\hline Surround force $(\mathrm{N})$ & 4 & $1,2,3,4,5$ and 6 \\
\hline Probe diameter (mm) & \multicolumn{2}{|c|}{6} \\
\hline Probe- surround gap $(\mathrm{mm})$ & \multicolumn{2}{|c|}{2} \\
\hline
\end{tabular}


Table 2 Statistical significance of the effects of variations in probe height $(0,1,2,3$ and 4 $\mathrm{mm}$ ) on vibrotactile thresholds ( ${ }^{*} p<0.05 ;{ }^{* *} p<0.01$; Wilcoxon).

\begin{tabular}{|c|c|c|c|c|c|}
\hline & \multicolumn{5}{|c|}{ Probe height $(\mathrm{mm})$} \\
\hline & & 1 & 2 & 3 & 4 \\
\hline \multirow{4}{*}{$\begin{array}{c}\text { Hallux } \\
(20 \mathrm{~Hz})\end{array}$} & 0 & $0.002^{* *}$ & $0.001^{* *}$ & $0.001^{* *}$ & $0.001^{* *}$ \\
\hline & 1 & & 0.116 & $0.022^{*}$ & $0.004^{* *}$ \\
\hline & 2 & & & 0.195 & 0.683 \\
\hline & 3 & & & & 0.730 \\
\hline \multirow{4}{*}{$\begin{array}{l}\text { Hallux } \\
(160 \mathrm{~Hz})\end{array}$} & 0 & $0.009^{* *}$ & $0.001^{* *}$ & $0.001^{* *}$ & $0.001^{* *}$ \\
\hline & 1 & & $0.006^{\star *}$ & $0.001^{* *}$ & $0.001^{* *}$ \\
\hline & 2 & & & $0.001^{* *}$ & $0.001^{* *}$ \\
\hline & 3 & & & & $0.016^{*}$ \\
\hline \multirow{4}{*}{$\begin{array}{c}\text { Ball } \\
(20 \mathrm{~Hz})\end{array}$} & 0 & $0.005^{\star *}$ & $0.006^{* *}$ & $0.001^{* *}$ & $0.006^{* *}$ \\
\hline & 1 & & 0.167 & $0.001^{\text {** }}$ & 0.064 \\
\hline & 2 & & & 0.177 & 0.451 \\
\hline & 3 & & & & 0.510 \\
\hline \multirow{5}{*}{$\begin{array}{c}\text { Ball } \\
(160 \mathrm{~Hz})\end{array}$} & 0 & $0.002^{* *}$ & $0001^{* *}$ & $0.001^{* *}$ & $0001^{* *}$ \\
\hline & 1 & & $0.016^{*}$ & $0.001^{\text {** }}$ & $0.001^{\text {** }}$ \\
\hline & 2 & & & $0.048^{*}$ & $0.002^{* *}$ \\
\hline & 3 & & & & $0.003^{* \star}$ \\
\hline & & & & & \\
\hline
\end{tabular}


Table 3 Statistical significance of the effects of variations in surround force $(1,2,3,4,5$, and $6 \mathrm{~N}$ ) on vibrotactile thresholds ( ${ }^{*} p<0.05 ;{ }^{* *} p<0.01$; Wilcoxon).

\begin{tabular}{|c|c|c|c|c|c|c|}
\hline & \multicolumn{6}{|c|}{ Surround force $(\mathrm{N})$} \\
\hline & & 2 & 3 & 4 & 5 & 6 \\
\hline \multirow{5}{*}{$\begin{array}{c}\text { Hallux } \\
(20 \mathrm{~Hz})\end{array}$} & 1 & $0.019^{*}$ & $0.006^{* *}$ & $0.008^{* *}$ & $0.002^{* *}$ & $0.002^{* *}$ \\
\hline & 2 & & 0.363 & 0.198 & $0.038^{*}$ & $0.012^{*}$ \\
\hline & 3 & & & 0.701 & 0.331 & 0.060 \\
\hline & 4 & & & & 0.286 & $0.035^{*}$ \\
\hline & 5 & & & & & 0.875 \\
\hline \multirow{5}{*}{$\begin{array}{c}\text { Hallux } \\
(160 \mathrm{~Hz})\end{array}$} & 1 & 0.683 & 0.158 & $0.016^{*}$ & $0.006^{\star *}$ & $0.002^{* *}$ \\
\hline & 2 & & 0.331 & $0.008^{* *}$ & $0.002^{* *}$ & $0.006^{\star *}$ \\
\hline & 3 & & & 0.096 & $0.035^{\star}$ & $0.048^{*}$ \\
\hline & 4 & & & & $0.041^{*}$ & 0.055 \\
\hline & 5 & & & & & 0.551 \\
\hline \multirow{5}{*}{$\begin{array}{c}\text { Ball } \\
(20 \mathrm{~Hz})\end{array}$} & 1 & 0.184 & $0.017^{*}$ & $0.048^{*}$ & $0.045^{*}$ & $0.013^{*}$ \\
\hline & 2 & & 0.683 & 0.248 & 0.258 & $0.048^{*}$ \\
\hline & 3 & & & 0.875 & 0.379 & 0.064 \\
\hline & 4 & & & & 1.000 & 0.187 \\
\hline & 5 & & & & & 0.433 \\
\hline \multirow{6}{*}{$\begin{array}{c}\text { Ball } \\
(160 \mathrm{~Hz})\end{array}$} & 1 & 0.331 & 0.177 & 0.124 & $0.026^{*}$ & 0.109 \\
\hline & 2 & & 0.245 & 0.683 & 0.209 & 0.510 \\
\hline & 3 & & & 0.925 & 0.594 & 0.683 \\
\hline & 4 & & & & 0.730 & 0.975 \\
\hline & 5 & & & & & 0.198 \\
\hline & & & & & & \\
\hline
\end{tabular}




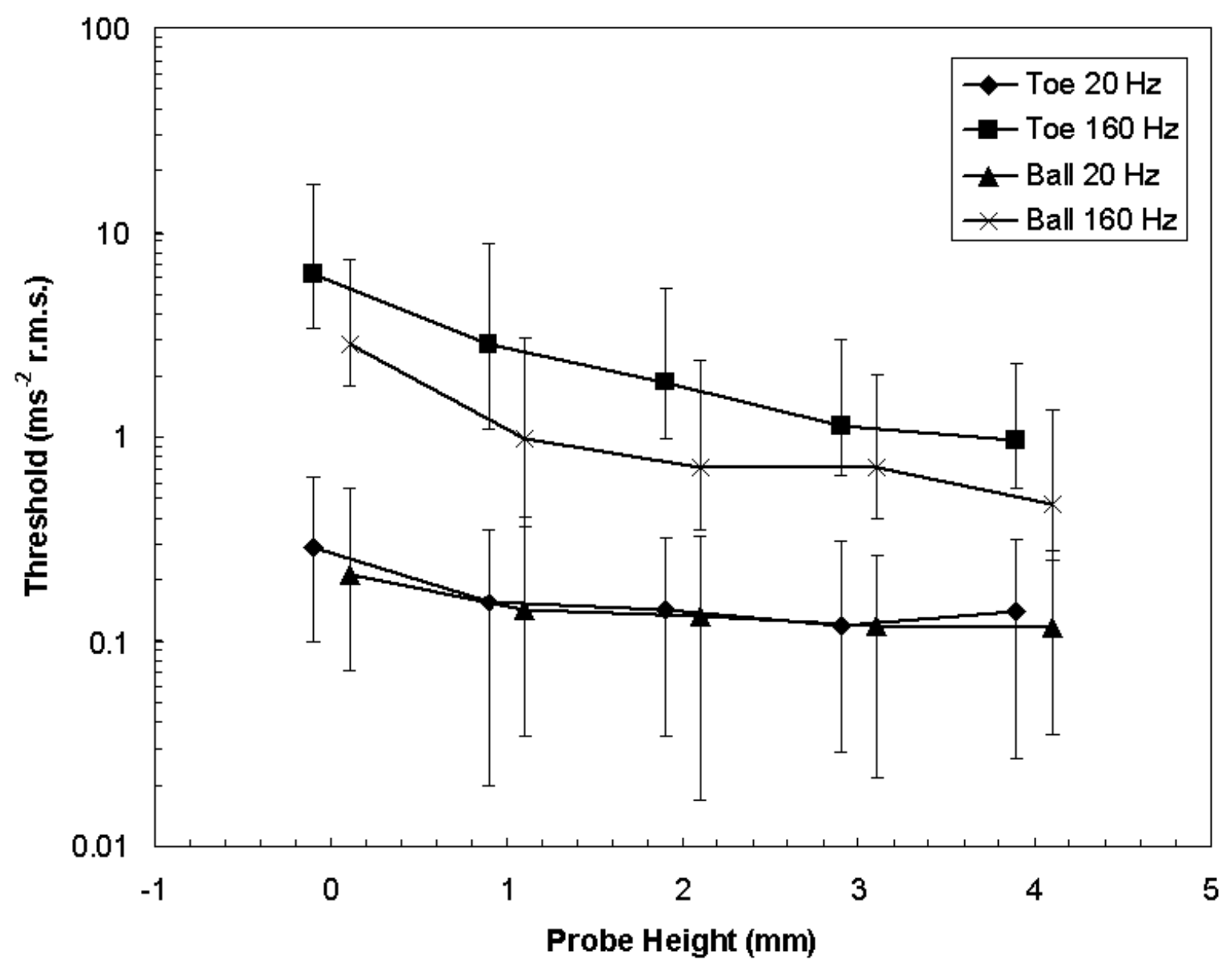

Figure 1 Median thresholds and inter-quartile ranges for fourteen subjects obtained with probe heights of $0,1,2,3$ and $4 \mathrm{~mm}$ above the surround at 20 and $160 \mathrm{~Hz}$ at the hallux and the ball of the foot. 


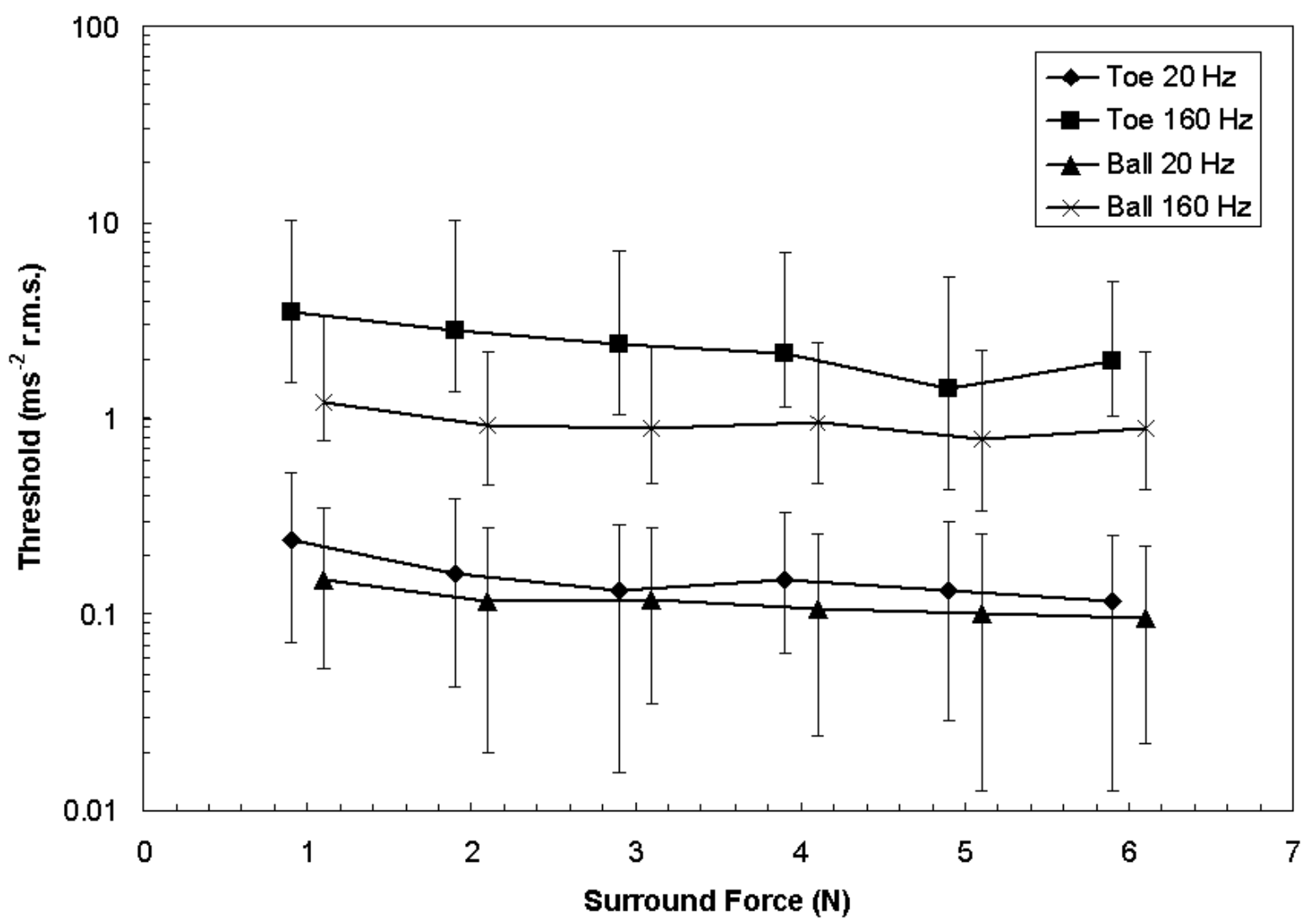

Figure 2 Median thresholds and inter-quartile range for fourteen subjects obtained with 1, 2, $3,4,5$ and $6 \mathrm{~N}$ surround force at 20 and $160 \mathrm{~Hz}$ at the hallux and the ball of the foot. 